\title{
Central auditory processing and migraine: a controlled study
}

\author{
Larissa Mendonça Agessi ${ }^{1,2^{*}}$, Thaís Rodrigues Villa ${ }^{1,2}$, Karin Ziliotto Dias ${ }^{1,2}$, Deusvenir de Souza Carvalho ${ }^{1,2}$ \\ and Liliane Desgualdo Pereira ${ }^{1,2}$
}

\begin{abstract}
Background: This study aimed to verify and compare central auditory processing (CAP) performance in migraine with and without aura patients and healthy controls.

Methods: Forty-one volunteers of both genders, aged between 18 and 40 years, diagnosed with migraine with and without aura by the criteria of "The International Classification of Headache Disorders" (ICDH-3 beta) and a control group of the same age range and with no headache history, were included. Gaps-in-noise (GIN), Duration Pattern test (DPT) and Dichotic Digits Test (DDT) tests were used to assess central auditory processing performance.

Results: The volunteers were divided into 3 groups: Migraine with aura (11), migraine without aura (15), and control group (15), matched by age and schooling. Subjects with aura and without aura performed significantly worse in GIN test for right ear ( $p=.006)$, for left ear $(p=.005)$ and for DPT test $(p<.001)$ when compared with controls without headache, however no significant differences were found in the DDT test for the right ear $(p=.362)$ and for the left ear $(p=.190)$.
\end{abstract}

Conclusions: Subjects with migraine performed worsened in auditory gap detection, in the discrimination of short and long duration. They also presented impairment in the physiological mechanism of temporal processing, especially in temporal resolution and temporal ordering when compared with controls. Migraine could be related to an impaired central auditory processing.

Clinical trial registration: Research Ethics Committee (CEP 0480.10) - UNIFESP

Keywords: Migraine; Central auditory processing; Memory; Attention; Auditory cortex

\section{Background}

Migraine is a neurological disease associated with an altered cortical excitability level [1]. Neurophysiological reports have shown that migraine is associated with abnormal excitability in visual, somatosensory and motor cortices [2-5]. The prevalence of migraine in Brazil is $15.2 \%$, and migraine is more frequent in women and in individuals with higher education [6].

There is evidence that migraine patients could present cognitive deficits, being the affected functions memory, processing information speed and attention [7]. The cognitive dysfunction is present in the interictal phase and during

\footnotetext{
* Correspondence: agessi.larissa@gmail.com

'Division of Investigation and Treatment of Headaches (DITH), Neurology and Neurosurgery Department, Federal University of São Paulo, UNIFESP, São Paulo, SP, Brazil

${ }^{2}$ Speech Pathology and Audiology Department, Federal University of São Paulo, UNIFESP, São Paulo, SP, Brazil
}



migraine attacks [8]. Neuropsychological exams combined with imaging methods showed the existence of cortical dysfunction associated with impaired cognition [7].

The auditory ability to recognize, identify, and sequence sounds involves perceptual and cognitive processes [9].

Central auditory perception (CAP) can be assessed by behavioural tests, which demonstrate good correlations with electrophysiological measures [10].

Previous research has reported abnormalities in the auditory brainstem response (ABR). These results were an indicator of impending auditory malfunction in migraine and disruption of central sensory processing mechanisms could be one of the mechanisms predisposing a migraine sufferer to the increase in sensitive to sound, resulting in phonophobia [11]. In line with these symptoms, long-term and short-term habituation of auditory event-related potentials 
have revealed abnormal auditory processing in migraine, both interictally and during attacks [12].

In previous studies the multifeature sound mismatch negativity (MMN) was evaluated in children and adults with migraine and women eith menstrualy-related migraine [13-15]. In the pediatric population, a decrease in M150 amplitude during the migraine attack was observed [13]. In adults with migraine with aura, an increased N1 was reported, suggesting a hypoactivity of automatic cortical processes [14]. Interestingly, in the group of patients with menstrualy-related migraine was observed normal auditory sensory processing but increased automatic attention orienting processes to auditory changes [15].

The definition of CAP is based on auditory functions [16]. CAP involves a large number of skills which are highly dependent on a set integrity of the auditory pathways, from the outer ear to the auditory cortex. These skills include auditory selective attention, sound detection, localization, discrimination of isolated and sequential sounds, as well as speech recognition, auditory comprehension and memory [16-18].

CAP is an indispensable tool for the investigation of the function of the central nervous system [19]. The impairment of auditory processing could cause difficulties in complex listening situations, such as understanding speech in back-ground noise, rapid or degraded speech, and problems with comprehending verbal instructions $[18,20]$.

A recent study that evaluated children with primary headache showed a deficit of auditory processing in noisy background compared to control cases [21].

The present study compared CAP performance between patients with migraine with and without aura and healthy controls.

\section{Methods}

\section{Participants}

Adults from both genders, aged between 18 and 40 years, were recruited via an advertisement in local community (São Paulo city). All the participants were assessed by the same headache specialist, at out-patient Division of Investigation and Treatment of Headaches (DITH), at the Federal University of Sao Paulo (UNIFESP). They were divided into two groups according to the International Headache Classification (ICDH-3 beta) criteria [22], confirmed by a completed 30-day filled headache diary: migraine with aura group (MA) and migraine without aura group (MwA). The control group (CG) had no previous history of headaches in the year prior to the study, and no migraine headaches in their lifetime.

Volunteers were excluded if their medical history and/ or neurological exam suggested other neurological, psychiatric and systemic disorders, head trauma, hearing loss, ear trauma surgery or history of ototoxicity, use of medication (including migraine prophylaxis), occupational noise exposure, and the history of drug abuse or dependency, including that related to alcohol consumption and cigarette smoking. However, participants who used medication for acute attacks were allowed in the experiment.

Both migraineurs groups and controls were matched by age and schooling (counted in years from the elementary school).

The study was approved by the local ethical committee (trial register: CEP 0480.10 UNIFESP) and all subjects signed an informed consent form before participation. The data was collected between June 2011 and April 2012.

Gaps-in-Noise (GIN) test, duration pattern test (DPT) and dichotic digits test (DDT) were used to assess central auditory processing. All the procedures lasted $50 \mathrm{mi}-$ nutes and the tests were done in the same day. By the time the participants with migraine underwent the auditory processing assessment they had been symptom-free for at least of 3 days, according to the headache diary. The migraineurs had no attacks during and after the experiment.

The tests used to evaluate the central auditory processing were recorded on a compact disc, played on a CD player and passed through a GSI 61 audiometer to TDH-50 matched earphones.

\section{Gaps-in-noise (GIN) test}

The GIN [23] is composed of a series of 6-second segments of broadband noise containing 0 to 3 silent intervals or gaps per noise segment. The interstimulus interval between successive noise segments lasts 5 seconds and the gap durations presented are $2,3,4,5,6,8,10,12,15$ and 20 miliseconds. The number of gaps and the duration per segment is varied. Ten practice items precede the test. There were six segments for each gap duration on each list, and two lists were used. The subjects were instructed to raise their thumb as soon as they heard a gap. An error was counted if a subject failed to raise his/her thumb. If a subject raised his/her thumb, without a gap having occurred, a false-positive was counted. To establish shortest gap durations, subjects needed to score a minimum of four out six at one gap duration.

\section{Duration Pattern Test (DPT)}

The DPT test [24] is a sequence of three $1,000 \mathrm{~Hz}$ tones, each one had three tones with different tone duration. The tone duration varies, one lasting 250 milliseconds, referred to as short, and another of 500 milliseconds, referred to as long. The interstimulus intervals were maintained at 300 milliseconds between the sequential tones, and the rise-descent time was kept at $10 \mathrm{msec}$. The test sequences were presented at an intensity of $30 \mathrm{dBSL}$ based on the auditory thresholds in the frequencies between 500 and 2,000 $\mathrm{Hz}$ in both ears, with TDH-39 
earphones. The patients were instructed to repeat the three-tone sequence in the same order he/she had heard it. Before testing, five practice items are provided to each subject to ensure their understanding of the task.

\section{Dichotic digit test}

The dichotic digit Portuguese version [25] test is a list of dissylabic words (numbers) spoken simultaneously and dichotically. Subjects are asked to listen attentively and repeat. There are twelve lists divided into pairs, each one containing twenty numbers.

\section{Data analysis}

For statistical analysis, the data were normally distributed and ANOVA was applied. Tukey's HSD test was used for post-hoc comparisons. Statistical analyses were performed with the Statistica Software (StatSoft Inc). The significance level was $\mathrm{P}<0.05$.

\section{Results}

Forty one participants were included in the present study: 11 were participants of MA, from which 10 were female, and the average age was $29.5( \pm 5.8)$ years; 15 were participants of MwA, from which 14 were female, and the average age was $29.5( \pm 6.3)$ years; 15 participants of CG, from which 14 were female, and the average age was $29.1( \pm 5.0)$ years (as shown in Table 1 ).

DPT test results showed a statistically significant difference between the control group and both migraine groups $(\mathrm{p}<.001)$. No difference has been observed between the groups with migraine $(\mathrm{p}=0.131)$.

The MA had an inferior performance on the GIN test for the left ear $(p=.029)$ and the DPT test for both ears $(\mathrm{p}<.001)$. The MwA had a worse performance on the GIN test for the right ear $(\mathrm{p}=.005)$ and the left ear $(\mathrm{p}=.008)$ and on the DPT test for both ears $(\mathrm{p}=.003)$, when compared with the CG. There was no difference between migraineurs and controls on the DDT test (for the right ear $\mathrm{p}=.362$; for the left ear $\mathrm{p}=.190$ ) and between migraine groups in all tests (as observed in Table 2, Figures 1 and 2).

\section{Discussion}

The present study demonstrated that individuals with migraine had worse performance in some central auditory processing tests when compared with controls.

The GIN test was performed to assess the auditory ability of temporal resolution (which determines the detection threshold gap or very short silent intervals and is identified as an interruption of the sound stimulus) and the physiological mechanism of temporal processing [26]. Previous research observed, healthy subjects aged between 13 and 46 were evaluated and gap thresholds of $4.8 \mathrm{~ms}$ for the left ear and $4.9 \mathrm{~ms}$ for the right ear were observed [23]. A hundred young healthy adults aged between 18 and 31 years and obtained threshold gaps of $4.19 \mathrm{~ms}$ for both ears in a study [27]. A threshold gap of $3.9 \mathrm{~ms}$ for 10 adults was observed [28]. The results of the present study, based on our CG, approached the results found in the literature. A comparison of the descriptive measures showed that migraineurs had similar performance. Comparing groups of migraine patients and the control group showed different performance amongst the groups, to the detriment of both migraineur group. Previous studies have revealed that the GIN test is sensitive for confirming lesions in the central auditory nervous system [23]. The threshold gap of 18 individuals suffering with Parkinson's disease was evaluated, which showed a deficit of temporal resolution in these patients and hypothesised that a dysfunction exists in the cerebral cortex, especially in the auditory area [29]. The difference in performance on the GIN test between patients with migraine and the control group may denote a central auditory system dysfunction in migraineurs with and without aura. The temporal resolution is essential for speech perception [30].

The DPT test was designed to evaluate the auditory ability of temporal ordering and the physiological mechanism of temporal processing. The normal Brazilian average percentage of correct answers was $83 \%$ in a study, that used stimuli with the duration of 250 milliseconds and 500 milliseconds in the ears [31].

Table 1 Demographic and clinical characteristics of the groups

\begin{tabular}{|c|c|c|c|c|}
\hline $\begin{array}{c}\text { Demographic and clinical characteristics of the } \\
\text { studied groups }\end{array}$ & Migraine with aura $(n=11)$ & Migraine without aura $(n=15)$ & Controls $(n=15)$ & $\begin{array}{l}\text { p-value } \\
\text { ANOVA }\end{array}$ \\
\hline Male/female & $10 / 1$ & $14 / 1$ & $14 / 1$ & \\
\hline Scholarity (years) & $14.5( \pm 2.8)$ & $14.9( \pm 2.1)$ & $14.8( \pm 2.2)$ & 0.8 \\
\hline Age (years) & $29.3( \pm 5.8)$ & $29.5( \pm 6.3)$ & $29.1( \pm 5.0)$ & 0.9 \\
\hline Positive family history of migraine & $72.7 \%$ & $86.7 \%$ & & \\
\hline Attacks frequency (number per month) & $8.2( \pm 4.1)$ & $7.5( \pm 2.3)$ & & 0.6 \\
\hline Duration of illness (years) & $17.4( \pm 7.1)$ & $12.5( \pm 6.9)$ & & 0.08 \\
\hline
\end{tabular}

Data presented as mean (SD) for continuos variables (age, scholarity, attacks frequency and duration of illness) and $\mathrm{n}$ (\%) for categorical variables (positive family history of migraine). 
Table 2 Results of the central auditory processing tests of patients with migraine with aura, patients without aura and the controls

\begin{tabular}{|c|c|c|c|c|c|c|c|c|c|c|c|c|c|c|c|c|}
\hline \multirow[t]{2}{*}{ Auditory processing test } & \multicolumn{5}{|c|}{ Migraine with aura group } & \multicolumn{5}{|c|}{ Migraine without aura group } & \multicolumn{6}{|c|}{ Control group } \\
\hline & Ave & SD & Min & Max & Med & Average & SD & Min & Max & Med & Average & SD & Min & Max & Med & $p$-value \\
\hline Gaps-in-Noise, RE & 5.45 & 1.13 & 4 & 8 & 5 & 5.87 & 2.1 & 2 & 10 & 5 & 4.07 & 0.8 & 3 & 5 & 4 & 0.006 \\
\hline Gaps-in-Noise, LE & 5.45 & 1.13 & 4 & 8 & 5 & 5.6 & 1.76 & 2 & 10 & 5 & 4.07 & 0.8 & 3 & 5 & 4 & 0.005 \\
\hline Duration pattern test & $68.90 \%$ & $11.80 \%$ & $56.0 \%$ & $84.0 \%$ & $63.0 \%$ & $77.90 \%$ & $14.60 \%$ & $46.0 \%$ & $100 \%$ & $80 \%$ & $92.80 \%$ & $6.70 \%$ & $76.0 \%$ & $96.5 \%$ & $96.4 \%$ & $<0.001$ \\
\hline Dichotic digit test, RE & $98.50 \%$ & $2.30 \%$ & $92.5 \%$ & $100 \%$ & $100 \%$ & $97.90 \%$ & $6.10 \%$ & $76.3 \%$ & $100 \%$ & $100 \%$ & $99.90 \%$ & $0.30 \%$ & $98.8 \%$ & $100 \%$ & $100 \%$ & 0.362 \\
\hline Dichotic digit test, LE & $98.90 \%$ & $1.80 \%$ & $95 \%$ & $100 \%$ & $100 \%$ & $98.80 \%$ & $2.60 \%$ & $90 \%$ & $100 \%$ & $100 \%$ & $99.90 \%$ & $0.30 \%$ & $98.8 \%$ & $100 \%$ & $100 \%$ & 0.190 \\
\hline
\end{tabular}

Abbreviations: LE left ear, RE right ear, SD standard deviation, Min minimum, Max maximum, Med Median. Significant $\mathrm{p}$ values $(\mathrm{p}<0.05)$ are printed in bold. 


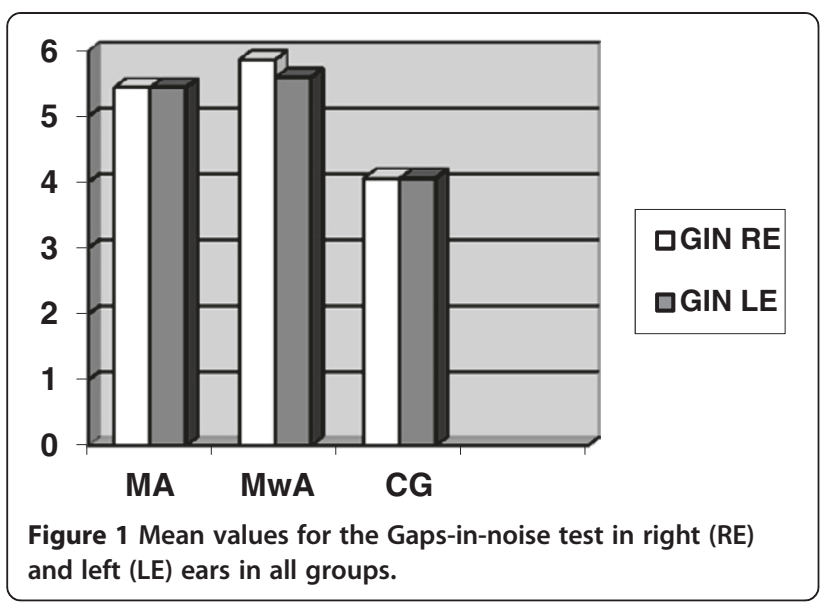

The perception of sound stimuli of up to 500 milliseconds involves a basic perceptual sensory mechanism [32]. The neuroanatomical substrate of sound duration discrimination of approximately $300 \mathrm{~ms}$ comprises 2 neural networks: a cortical frontal-parietal area (which is responsible for attentional focus to sensory stimuli) and areas involving the basal ganglia, cerebellum, and right prefrontal cortex which are more specifically related to temporal aspects of sound duration discrimination [33]. The DPT detects cortex and inter-hemispheric dysfunctions [34].

In the present study, the average percentages of correct answers from the DPT test were below normal for the groups with migraine-especially for the MA-and within the normal range for the CG. And we therefore observed perceptual impairment in basic sensory processing in migraineurs with and without aura.

The DDT is used to evaluate the figure-ground ability for verbal sounds by using dichotic listening/binaural integration. For an ordinary performance in the DDT, it is necessary that information crosses the corpus callosum and reaches the language-dominant hemisphere. Previous studies suggested that abnormal results in both ears indicate changes in the left hemisphere [35].

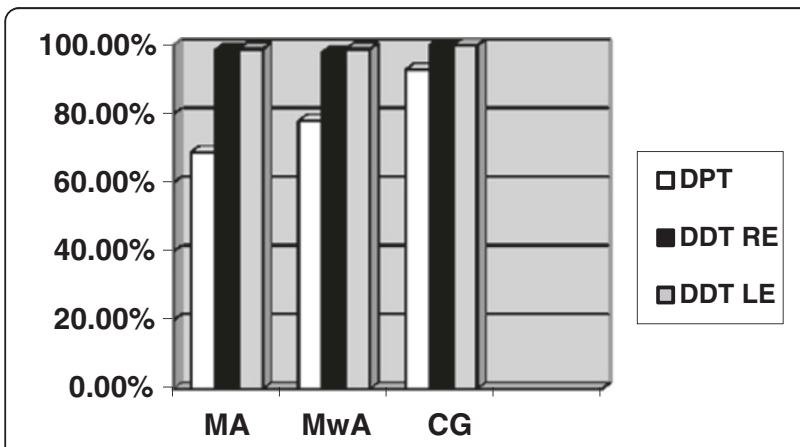

Figure 2 Mean values for DPT and DDT for right (RE) and left (LE) ears in all groups.
The results of this study showed no statically significant difference between the groups that were studied and the performance of individuals within the normal range. Based on that, we could infer that the figure-ground ability for verbal sounds was preserved in people with migraine.

Finally, it should be noted that, some previous studies have shown that migraineurs, in the intercritical phase and in the migraine attack, have abnormalities in the function of neural substrates, responsible for different stages of auditory processing $[11,13]$.

This study had some limitations, including, for example, sample size and gender distribution. The highlights were the selection method which excludes critically ill migraine patients - and the presence of a healthy control group. Further investigation, with larger samples, would be necessary to confirm our findings.

\section{Conclusions}

Patients with migraine had an inferior performance in auditory gap detection and in the discrimination of short and long durations, and presented impairment in the physiological mechanism of temporal processing, especially in temporal resolution and temporal ordering when compared with controls. These difficulties could reflect on auditory memory and attention deficits. Migraine could be related to an impaired central auditory processing.

\section{Abbreviations}

et al:: and others (from the Latin, "et alli"); ICHD - 3 beta: "The International Classification of Headache Disorders- third edition ", (2011); UNIFESP: Federal University of São Paulo; GIN: Gaps-in-noise; DPT: Duration Pattern Test; DDT: Dichotic digit test; CAP: Central auditory processing; MA: Migraine with aura group; MwA: Migraine without aura group; CG: Control group.

\section{Competing interests}

The authors declare that they have no competing interests.

\section{Authors' contributions}

LMA, MD TRV, MD KZD, MD DSC and MD LDP carried out the studies. LMA carried out the audiological evaluation. LDP and KZD supervised the audiological evaluation. LMA and TRV drafted the manuscript. LMA, TRV and LDP participated in the design of the study, performed the statistical analysis and discussed the data interpretation. TRV, KZD, DSC and LDP reviewed the manuscript and provided useful advice. All authors read and approved the final manuscript.

Information of financial support for research

With financial aid- FAPESP- São Paulo Research Foundation.

Received: 7 September 2014 Accepted: 29 October 2014

Published: 8 November 2014

\section{References}

1. Coppola G, Pierelli F, Schoenen J (2009) Habituation and migraine. Neurobiol Learn Mem 92:249-259

2. Bowyer SM, Aurora KS, Moran JE, Tepley N, Welch KM (2001) Magnetoencephalographic fields from patients with spontaneous and induced migraine aura. Ann Neurol 50(5):582-587

3. Lang E, Kaltenhäuser M, Neundörfer B, Kaltenhäuser M, Seidler S (2004) Hyperexcitability of the primary somatosensory cortex in migraine: a magnetoencephalographic study. Brain 127(11):2459-2469

4. Gunaydin S, Soysal A, Atay T, Arpaci B (2006) Motor and occipital cortex excitability in migraine patients. Can J Neurol Sci 33(1):63-67 
5. Ge HT, Liu HX, Xiang J, Miao AL, Tang L, Guan QS, Wu T, Chen QQ, Yang L, Wang XS (2014) Abnormal cortical activation in females with acute migraine: a magnetoencephalography study. Clin Neurophisiol. [epub ahead to print]

6. Queiroz LP, Peres MF, Piovesan EJ, Kowacs F, Ciciarelli MC, Souza JA, Zukerman E (2009) A nationwide population-based study of migraine in Brazil. Cephalalgia 29(6):642-649

7. Calandre EP, Bembibre J, Arnedo ML, Becerra D (2002) Cognitive disturbances and regional cerebral blood flow abnormalities in migraine patients: their relationship with the clinical manifestations of the illness. Cephalalgia 22:291-302

8. Hooker WD, Raskin NH (1986) Neuropsychologic alterations in classic and common migraine. Arch Neurol 43:709-712

9. Pinheiro M, Musiek F (1985) Assessment of Central Auditory Dysfunction: Foundations and Clinical Correlates. Baltimore, Willianms \& Wilkins

10. Wible B, Nicol T, Kraus N (2005) Correlation between brainstem and cortical auditory processes in normal and language-impaired children. Brain 128:417-423

11. Hamed SA, Youssef AH, Elattar AM (2011) Assessment of cochlear and auditory pathways in patients with migraine. Am J Otolaryngol 33:385-394

12. Demarquay G, Caclin A, Brudon F, Fischer C, Morlet D (2011) Exacerbated attention orienting to auditory stimulation in migraine patients. Clin Neurophisiol 122(9):1755-1763

13. Korostenkaja M, Pardos M, Kujala T, Rose DF, Brown D, Horn P, Wang $Y$, Fujiwara H, Xiang J, Kabbouche MA, Powers SW, Hershey AD (2011) Impaired auditory information processing during acute migraine: a magnoencephalography study. Int J Neurosci 121:355-365

14. de Tommaso M, Guido M, Libro G, Losito L, Difruscolo O, Sardaro M, Puca FM (2004) Interictal lack of habituation of mismatch negativity in migraine. Cephalalgia 24:663-668

15. Morlet D, Demarquay G, Brudon F, Fischer C, Caclin A (2014) Attention orienting dysfunction with preserved automatic auditory change detection in migraine. Clin Neurophysiol 125(3):500-511

16. Philips DP (1995) Central Auditory Processing: a view from auditory neuroscience. Am J Otol 16:338-352

17. American Speech-language-Hearing Association (ASHA) (1996) Central auditory processing: current status of research and implications for clinical practice. Am J Audiol 5:41-54

18. Chermak GD (2002) Deciphering auditory processing disorders in children. Otolaryngol Clin North Am 35:733-749

19. Koelsch S, Walter A (2005) Towards a neural basis of music perception. Trend Cogn Sci 9:12

20. Jerger J, Musiek F (2000) Report of the consensus conference on the diagnosis of auditory processing disorders in school-aged children. J Am Acad Audiol 11:467-474

21. Ciriaco A, Russo A, Monzani D, Genovese E, Benincasa P, Caffo E, Pini L (2013) A preliminary study on the relationship between central auditory processing and childhood primary headaches in the intercritical phase. J Headache Pain 14:69

22. Headache Classification Subcommittee of the International Headache Society (2013) The international classification of headache disorders. Cephalalgia 33(9):629-808

23. Musiek FE, Shinn JB, Jirsa R, Bamiou DE, Baran JA, Zaida E (2005) The GIN (Gaps-in-Noise) test performance in subjects with confirmed central auditory nervous system involvement. Ear Hear 26:608-618

24. Musiek FE, Baran JA, Pinheiro ML (1990) Duration pattern recognition in normal subjects and patients with cerebral and cochlear lesions. Audiology 29(6):304-313

25. Santos MFC, Pereira LD (1997) Escuta com Dígitos. In: Pereira LD, Schochat E (eds) Processamento Auditivo Central: Manual de Avaliação. Lovise, São Paulo, pp 147-150

26. Musiek FE, Zaidan EP, Baran JB, Shinn JB, Jirsa RE (2004) Assessing Temporal Processes in Adults With LD: The GIN Test. In: Convention of the American Academy of Audiology, Salt Lake City, 2004 March-April. Annals. AAA, Salt Lake City, p 203

27. Samelli AG, Schochat E (2008) The Gaps-in-Noise test: Gap detection thresholds in normal-hearing adults. Int J Audiol 47(5):238-245

28. Weihing J, Musiek FE, Shinn J (2007) The effect of presentation level on the Gaps-In-Noise (GIN) test. J Am Acad Audiol 18:141-150

29. Guehl D, Burbaud P, Lorenzi C, Ramos C, Bioulac B, Semal C, Demany L (2008) Auditory temporal processing in Parkinson's disease. Neuropsychologia 46:2326-2335
30. Huang Q, Tang J (2010) Age-related hearing loss or presbycusis. Eur Arch Otorhinolaryngol 267(8):1179-1191

31. Corazza MCA (1998) Avaliação do Processamento Auditivo Central em Adultos: Testes de Padrões Tonais Auditivos de Frequência e Teste de Padrões Tonais Auditivos de Duração. Tese de Doutorado [Doctoral Thesis]. Universidade Federal de São Paulo, São Paulo, Brazil

32. Grimm S, Widmann A, Schröger E (2004) Differential processing of duration changes within short and long sounds in humans. Neurosci Lett 356(2):83-86

33. Berlin P, McAdams S, Thivard L, Smith B, Savel S, Zibovicius M, Sanson S, Samson Y (2002) The neuroanatomical substrate of sound duration discrimination. Neuropsychologia 40:1956-1964

34. Castro LCD (2001) Avaliação do Processamento Auditivo Central em Indivíduos com Lesão Cerebral: Teste de Padrão de Duração. Tese de Mestrado [Master Thesis], São Paulo. Universidade Federal de São Paulo, São Paulo, Brazil

35. Kimura D (1967) Functional asymmetry of the brain in dichotic listening Cortex 3:163-178

doi:10.1186/1129-2377-15-72

Cite this article as: Agessi et al:: Central auditory processing and migraine: a controlled study. The Journal of Headache and Pain 2014 15:72.

\section{Submit your manuscript to a SpringerOpen ${ }^{\circ}$ journal and benefit from:}

- Convenient online submission

- Rigorous peer review

- Immediate publication on acceptance

- Open access: articles freely available online

- High visibility within the field

- Retaining the copyright to your article

Submit your next manuscript at $>$ springeropen.com 